\title{
Universal newborn hearing screening in the Lazio region, Italy
}

\author{
Rosaria Turchetta', Guido Conti ${ }^{2}$, Pasquale Marsella ${ }^{3}$, Maria Patrizia Orlando ${ }^{1}$, Pasqualina Maria Picciotti ${ }^{2}$, \\ Simonetta Frezza ${ }^{4}$, Francesca Yoshie Russo ${ }^{1}$, Alessandro Scorpecci ${ }^{3}$, Maria Gloria Cammeresi ${ }^{1}$, Sara Giannantonio ${ }^{3}$, \\ Antonio Greco ${ }^{1}$ and Massimo Ralli ${ }^{*}$ (D)
}

\begin{abstract}
Background: The introduction of Universal Newborn Hearing Screening (UNHS) programs has drastically contributed to the early diagnosis of hearing loss in children, allowing prompt intervention with significant results on speech and language development in affected children. UNHS in the Lazio region has been initially deliberated in 2012; however, the program has been performed on a universal basis only from 2015. The aim of this retrospective study is to present and discuss the preliminary results of the UNHS program in the Lazio region for the year 2016, highlighting the strengths and weaknesses of the program.

Methods: Data from screening facilities in the Lazio region for year 2016 were retrospectively analyzed. Data for Level I centers were supplied by the Lazio regional offices; data for Level II and III centers were provided by units that participated to the study.

Results: During 2016, a total of 44,805 babies were born in the Lazio region. First stage screening was performed on 41,821 children in 37 different birth centers, with a coverage rate of 93.3\%. Of these, 38.977 (93.2\%) obtained a "pass" response; children with a "refer" result in at least one ear were 2844 (6.8\%). Data from Level II facilities are incomplete due to missing reporting, one of the key issues in Lazio UNHS. Third stage evaluation was performed on 365 children in the three level III centers of the region, allowing identification of 70 children with unilateral (40\%) or bilateral (60\%) hearing loss, with a prevalence of 1.6/1000.

Conclusions: The analysis of 2016 UNHS in the Lazio region allowed identification of several strengths and weaknesses of the initial phase of the program. The strengths include a correct spread and monitoring of UNHS among Level I facilities, with an adequate coverage rate, and the proper execution of audiological monitoring and diagnosis among Level III facilities. Weakness, instead, mainly consisted in lack of an efficient and automated central process for collecting, monitoring and reporting of data and information.
\end{abstract}

Keywords: Universal newborn hearing screening, Hearing loss, A-TEOAE, ABR

\section{Background}

Hearing loss is one of the most common defects at birth occurring in about 1.4 babies per 1000 newborns $[1,2]$. Hearing impairment can affect a child's ability to develop speech, language and social skills [3]; a late diagnosis can severely impact on the future life of the child with serious disability and related high costs [4-6]. A recent study in the Italian population estimated that the lifetime mean

\footnotetext{
* Correspondence: massimo.ralli@uniroma1.it

'Department of Sense Organs, Sapienza University of Rome, Rome, Italy Full list of author information is available at the end of the article
}

cost for a subject with profound pre-lingual deafness is around $€ 700.000$ [7].

The early diagnosis and intervention in children with hearing loss at $<6$ months of age leads to significantly better outcomes for speech and language development compared to non-treated children $[8,9]$. Early diagnosis is based on Universal Newborn Hearing Screening (UNHS) programs; intervention relies on the use of hearing aids and cochlear implants [10]. It has been largely demonstrated that UNHS is the only effective way to evaluate the largest portion of population; when neonatal hearing screening is restricted to high risk

(c) The Author(s). 2018 Open Access This article is distributed under the terms of the Creative Commons Attribution 4.0 International License (http://creativecommons.org/licenses/by/4.0/), which permits unrestricted use, distribution, and 
groups, hearing impairment remains undiagnosed in 30$50 \%$ of infants [10-15]. Furthermore, in the absence of a UNHS program, moderate to severe hearing loss is not identified before a mean age of two years and not treated earlier than 40 months, while mild hearing impairment is identified even later, sometimes at school age [16].

Several Italian regions have introduced UNHS during the last decade, with different results and methodologies. In 2017, the Italian Ministry of Health introduced UNHS among the Essential Levels of Assistance (ELA). Lazio is a region in central Italy with an area of about $18,000 \mathrm{~km}^{2}$, a population of about six million inhabitants and 50.000 newborns every year. In the Lazio region, UNHS has been introduced in 2012 with Regional Council Resolution n. 115/2012 "Linea d'azione screening uditivo neonatale universale. Programma di attivazione e messa a regime", a document based on the national and international guidelines [14, 17]. However, UNHS has been performed regularly on a universal basis only from 2015. A graphical representation of the recommended algorithm for Universal Newborn Hearing Screening in the Lazio region is shown in Fig. 1.

The aim of this retrospective study is to present and discuss the results of the 2016 UNHS program in the Lazio region, highlighting the main strengths and weaknesses of the initial phase of the program.

\section{Methods}

\section{Operative and geographical organization}

UNHS was executed in all birth centers and neonatal intensive care units (NICU) of the region, homogenously distributed in the territory. Screening facilities, defined by the regional government in 2012 according to international guidelines, were divided into three different levels:

- Level I: includes most of birth centers and NICU, that can execute Transient Evoked Otoacoustic Emissions (TEOAE) only. TEOAE testing can be executed by trained nursing personnel, neonatologists and audiometrists. In the Lazio region, there are 37 Level I facilities. The original regional plan included 44 Level I centers; however, seven smaller centers were subsequently merged.

- Level II: these facilities, mainly available in middle and large hospitals, execute TEOAE and Automated Auditory Brainstem Responses (A-ABR). Tests can be executed by specifically trained personnel including pediatric nurses, audiometrists, pediatricians, audiologists, otolaryngologists. In the Lazio region, there are 11 Level II facilities.

- Level III: Level III centers, also named "reference centers", can perform the whole clinical and audiological evaluation in children, including testing clinical TEOAE, Distortion Product Otoacoustic
Emissions (DPOAE) and ABR, and lead to a complete diagnosis of hearing loss and the activation of the habilitation. In the Lazio region there are three Level III centers: the Policlinico Umberto I Hospital, the Agostino Gemelli Hospital, and the Bambino Gesù Pediatric Hospital.

Detailed data on facilities included in the UNHS in the Lazio region, and the corresponding Level III center are outlined in Table 1.

\section{Screening protocol}

UNHS should be performed in all newborns within $72 \mathrm{~h}$ after birth before discharge. Screening operative protocol is divided into three stages.

1. First Stage: initial screening performed on all newborns in both ears using TEOAE by trained personnel. TEOAE testing should be performed in a quiet environment when babies are asleep or feeding. In the case of a bilateral "pass" response, the screening is considered completed. In the case of a "refer" response in one or both ears, it is recommended to repeat the test before discharge. Newborns with a "refer" at this first stage evaluation are addressed to second stage evaluation within 15 days.

2. Second Stage: includes children that do not pass first stage screening in at least one ear and babies with a family history of sensorineural hearing loss or pregnancy or auditory neuropathy risk factors, according to the Joint Committee on Infant Hearing (JCIH) 2007, and is executed using A-ABR. Intrauterine risk factors include maternal infections, such as Toxoplasmosis, Syphilis, HIV, Hepatitis B, Rubella, Citomegalovirus, Herpes Simplex during pregnancy or delivery; admission to a NICU greater than five days; prematurity ( $<37$ weeks); exposure to ototoxic medications such as gentamycin, tobramycin and furosemide; hyperbilirubinemia that requires transfusion; syndromes associated with hearing impairment such as Pendred, Usher, Waardenburg, Neurofibromatosis; and craniofacial anomalies, including those involving the pinna, ear canal, ear tags, ear pits, and temporal bone anomalies (Table 2). All babies must be tested within the first month of life. In case of a bilateral "pass" response at A-ABR, the screening is considered completed. However, it is recommended that babies with known risk factors are monitored with TEOAE, ABR, acoustic immittance testing at regular intervals every six months for the first three years, then every twelve months for the following three years to identify children with late or progressive hearing loss. 


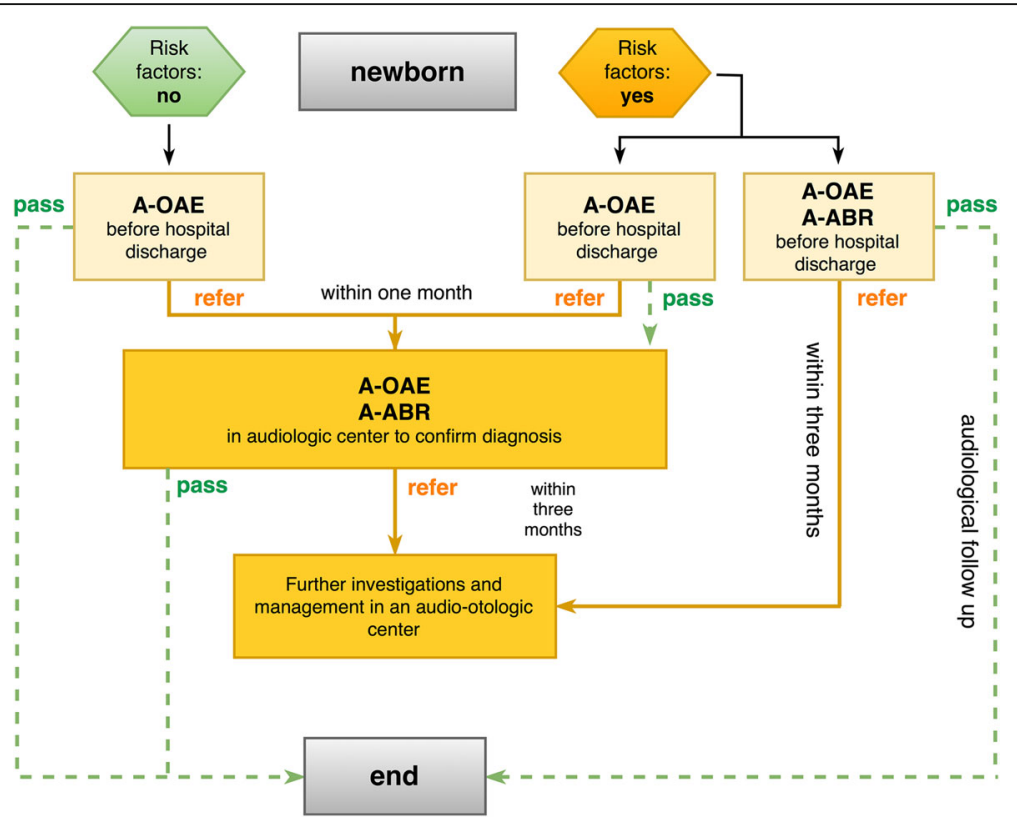

Fig. 1 Graphical representation of the recommended algorithm for Universal Newborn Hearing Screening in the Lazio region

3. Third Stage (clinical audiological evaluation): includes children that fail second stage testing in one or both ears. It is executed by level III facilities by means of case history, otoscopy, clinical TEOAE and/or DPOAE, ABR recording and impedance under supervision of experienced otolaryngologists or audiologists. All babies must be tested within the third month of life and should begin a prosthetic and rehabilitation treatment within six months of age.

\section{Data collection}

The following data for each Level I facility were provided by regional offices: number of children born alive; number of children tested; number of children with a "pass" response; number of children with a "refer" response. Such data were digitally tracked and transmitted by Level I facilities to the monitoring offices of the Lazio region.

Data from Level II facilities were provided only by four centers: Policlinico Umberto I, Policlinico Gemelli, Ospedale San Camillo Forlanini, Ospedale Pediatrico Bambino Gesù upon request. Data included: number of children referred from Level I facilities, although the referring center was not specified; number of children tested; number of children with a "pass" response; number of children with a "refer" response.

Complete data were provided from individual registries of the three Level III centers of the Lazio region: Policlinico Umberto I, Policlinico Gemelli, Ospedale Pediatrico Bambino Gesù. Data included: number of children referred to Level III centers; number of children tested; number of children with unilateral/bilateral hearing loss; degree of hearing loss (mild/moderate; severe/profound). No information was provided on risk factors of babies included in the screening protocol.

\section{Results}

During 2016, a total of 44,805 babies were born in the Lazio region. First stage screening was performed on 41,821 in 37 different birth centers. They included 26 public hospitals and 11 private hospitals and clinics. Overall coverage rate was $93.3 \%$. Territory distribution was as follows: 25 birth centers were in central Lazio (67.6\%); eight in southern Lazio (21.6\%) and four in northern Lazio (10.8\%). Among birth centers in central Lazio, 21 (84\%) were in the city of Rome. When first stage screening was not possible in a birth center, children were referred to other level I or II centers. Children that obtained a "pass" response at first stage screening were 38,977 (93.2\%); children with a "refer" result in at least one ear were 2844 (6.8\%). Detailed data on first stage screening performed during 2016 in the Lazio region are shown in Table 3.

Incomplete data reporting from Level II facilities did not allow a consistent analysis of second stage screening. Data were received only from four centers (36.4\%), in which second stage screening was performed on 1175 children; among these children, 49 (4.2\%) had own or maternal specific risk factors. One hundred-twenty-five children (10.6\%) failed second 
Table 1 Organization of universal newborn hearing screening in the Lazio region

\begin{tabular}{|c|c|c|c|}
\hline Territory & Level I & Level II & Level III \\
\hline Rome & San Giovanni Calibita - FBF & San Giovanni Calibita - FBF & Bambino Gesù Hospital \\
\hline Rome & Quisisana & & \\
\hline Rome & Villa Mafalda & & \\
\hline Rome & Villa Margherita & & \\
\hline Rome & Mater Dei & & \\
\hline Rome & Sant'Eugenio Hospital & Sant'Eugenio Hospital & Policlinico Umberto I Hospital \\
\hline Rome & San Giovanni Hospital & & \\
\hline Rome & Vannini Hospital & & \\
\hline Rome & Fabia Mater & & \\
\hline Rome & Annunziatella & & \\
\hline Rome & Policlinico Umberto I & Policlinico Umberto I Hospital & \\
\hline Rome & Policlinico Casilino & & \\
\hline Rome & Pertini Hospital & & \\
\hline Colleferro & Parodi Delfino & & \\
\hline Palestrina & Coniugi Berardini & & \\
\hline Tivoli & San Giovanni Evangelista & & \\
\hline Rome & Grassi Hospital & Grassi Hospital & \\
\hline Rome & Villa Pia & & \\
\hline Rome & Città di Roma & & \\
\hline Rome & San Camillo Hospital & San Camillo Hospital & \\
\hline Rome & Policlinico Gemelli & Policlinico Gemelli & Policlinico Gemelli \\
\hline Rome & Santo Spirito Hospital & & \\
\hline Rome & Santa Famiglia & & \\
\hline Rome & Cristo Re & & \\
\hline Rome & San Pietro - FBF & Bambino Gesù Hospital & Bambino Gesù Hospital \\
\hline Rome & Aurelia Hospital & & \\
\hline Rome & Santa Maria di Leuca & & \\
\hline Rome & San Filippo Neri & & \\
\hline Civitavecchia & San Paolo Hospital & & \\
\hline Anzio & P.O. Anzio Nettuno & & \\
\hline Albano Laziale & P.O. Albano & & \\
\hline Marino & San Giuseppe & & \\
\hline Velletri & Civile Paolo Colombo & & \\
\hline Latina & P.O. Latina Nord & P.O. Latina Nord & \\
\hline Terracina & P.O. Latina Centro & & \\
\hline Formia & P.O. Latina Sud & & \\
\hline Aprilia & Città di Aprilia & & \\
\hline Tarquinia & Civile di Tarquinia & Belcolle Hospital & Policlinico Gemelli \\
\hline Viterbo & Belcolle Hospital & & \\
\hline Rieti & P.O. Rieti & P.O. Rieti & \\
\hline Frosinone & Spaziani Hospital & Spaziani Hospital & \\
\hline Alatri & San Benedetto & & \\
\hline Sora & Santissima Trinità & & \\
\hline Cassino & Santa Scolastica & & \\
\hline
\end{tabular}


Table 2 Audiological risk factors

Audiological risk factor - JClH

Family history of hereditary childhood sensorineural hearing loss

In-utero infection (e.g., rubella, cytomegalovirus, syphilis, toxoplasmosis, herpes) Craniofacial anomalies

Low birth weight (b1500 g or $3.3 \mathrm{lb}$ )

Hyperbilirubinemia at levels requiring exchange transfusion

Bacterial meningitis

Exposure to ototoxic medications

Mechanical ventilation lasting 5 days or longer

Stigmata or other findings associated with a syndrome known to include a sensorineural and/or conductive hearing loss

Apgar scores of $0-4$ at $1 \mathrm{~min}$ or $0-6$ at 5 min

Admission to the Neonatal Intensive Care Unit (NICU)

Parent/caregiver concern regarding hearing, speech, language, and/or developmental delay

Head trauma associated with loss of consciousness or skull fracture

Recurrent or persistent otitis media with effusion lasting for at least 3 months

Audiological risk factor according to the Joint Committee on Infant Hearing $(\mathrm{JClH})$

stage screening and were referred to Level III centers for clinical diagnosis of hearing loss.

Third stage evaluation was performed on 365 children in the Level III centers of the Lazio region. They included children that failed second stage testing and children that were referred by other hospitals for risk factors. Data are summarized in Table 4.

- Policlinico Umberto I: 44 children were referred for clinical hearing evaluation; 33 were children that did not pass second stage screening (21 in the same center, 11 in a different hospital), 12 were referred for risk factors. Two children dropped out and could not be tested. Of tested children, 18 had normal clinical ABR in both ears and were considered having normal hearing; 24 were diagnosed with clinical hearing loss (13 unilateral, 11 bilateral), and they included four children with risk factors. Children with bilateral hearing impairment had profound hearing loss in two cases, severe in three cases, and moderate in six cases; children with unilateral hearing impairment had profound hearing loss in three cases, severe in two cases, moderate in five cases, and mild hearing loss in three cases.

- Policlinico Gemelli: 114 children were referred to this center for clinical hearing evaluation; 39 failing second stage screening (32 from same center, 7 from a different center) and 75 for risk factors. Sixty-six children dropped out and could not be tested. Forty-eight children underwent clinical ABR; 31 had normal hearing and 17 were diagnosed with clinical hearing loss (nine unilateral, eight bilateral). All children with bilateral hearing impairment had a moderate hearing loss in both ears (one had moderate hearing loss in one ear and mild in the other); children with unilateral hearing impairment had a profound hearing loss in two cases, severe in one case, mild in six cases.

- Ospedale Pediatrico Bambino Gesù: 207 children were tested with clinical ABR. Of these, 29 were diagnosed with unilateral (6/29) or bilateral (23/29) hearing loss. Children with bilateral hearing impairment had profound hearing loss in 11 cases, severe in four cases, and moderate in seven cases; children with unilateral hearing impairment had profound hearing loss in one case, severe hearing loss in two cases, and moderate in three cases.

The total number of children diagnosed with unilateral or bilateral hearing impairment during 2016 by Level III centers in the Lazio region was 70 , with a prevalence of $1.6 / 1000$. Children with a diagnosis of unilateral hearing loss were $28(0.62 / 1000)$, while children with bilateral hearing impairment were $42(0.93 / 1000)$. Incomplete data reporting does not allow calculating specific data for well born babies and babies with risk factor.

\section{Discussion}

This is the first study that analyses the results of the UNHS in the Lazio region. Previous studies in other Italian regions include Liguria [18], Umbria [19], Tuscany [20], Campania [21] and Sicily [22], while other reports focused on specific cities or hospitals, such as the Ferrara [23], Pisa [24], Parma [25], Milan [26] and Siena experiences [27]. Our study shows a coverage rate in the Lazio region in 2016 of $93.3 \%$, which is close to the recommendations by the JCIH guidelines that require a minimum coverage rate for the newborn population of $95 \%$ and a percentage of false positive $<3 \%$ [14]. The coverage rate of the Lazio region is also in line with national averages, that have consistently increased over the past years. In the past, a study from Bubbico et al. [28] investigated the evolution of the coverage rate of UNHS in several Italian regions from 2003 to 2011, showing a progressive increase of coverage that reached in 2011 a national average of $78.3 \%$; coverage exceeded $95 \%$ in $12 / 20$ regions especially in the North West and North East regions, while some areas such as the main islands still showed a limited diffusion of hearing screening programs. In 2017 the Italian Ministry of Health introduced UNHS among the ELA; this will allow a further increase of the coverage rate in the upcoming years.

UNHS in the Lazio region allowed identification of 70 children diagnosed with unilateral $(40 \%)$ or bilateral (60\%) hearing loss during 2016, with a prevalence of 1.6/1000. 
Table 3 First stage screening results

\begin{tabular}{|c|c|c|c|c|c|c|}
\hline BIRTH CENTERS & BORN ALIVE & TESTED & $\%$ TESTED & PASS & REFER & \% REFER \\
\hline San Giovanni FBF & 3643 & 3580 & $98,27 \%$ & 3552 & 28 & $0,78 \%$ \\
\hline Quisisana & 84 & 41 & $48,81 \%$ & 41 & 0 & $0,00 \%$ \\
\hline Villa Mafalda & 30 & 5 & $16,67 \%$ & - & - & - \\
\hline Villa Margherita & 132 & 94 & $71,21 \%$ & 94 & 0 & $0,00 \%$ \\
\hline San Giovanni Addolorata & 337 & 337 & $100,00 \%$ & 289 & 48 & $14,24 \%$ \\
\hline Sant'Eugenio & 1107 & 1102 & $99,55 \%$ & 1018 & 84 & $7,62 \%$ \\
\hline M.G. Vannini & 300 & 291 & $97,00 \%$ & 279 & 12 & $4,12 \%$ \\
\hline Fabia Mater & 1730 & 622 & $35,95 \%$ & 600 & 22 & $3,54 \%$ \\
\hline Pol. Umberto I & 1641 & 1551 & $94,52 \%$ & 1307 & 244 & $15,73 \%$ \\
\hline Pol. Casilino & 2746 & 2710 & $98,69 \%$ & 2613 & 97 & $3,58 \%$ \\
\hline Sandro Pertini & 1152 & 1075 & $93,32 \%$ & 1045 & 30 & $2,79 \%$ \\
\hline Con. Bernardini (Palestrina) & 705 & 697 & $98,87 \%$ & 670 & 27 & $3,87 \%$ \\
\hline San Giovanni E. (Tivoli) & 678 & 666 & $98,23 \%$ & 605 & 61 & $9,16 \%$ \\
\hline GB. Grassi & 1711 & 1700 & $99,36 \%$ & 1680 & 20 & $1,18 \%$ \\
\hline Città di Roma & 1278 & 1269 & $99,30 \%$ & 1264 & 5 & $0,39 \%$ \\
\hline San Camillo Forlanini & 2580 & 2645 & $102,52 \%$ & 2352 & 293 & $11,08 \%$ \\
\hline S. Spirito & 643 & 633 & $98,44 \%$ & 622 & 11 & $1,74 \%$ \\
\hline Santa Famiglia & 1833 & 1829 & $99,78 \%$ & 1815 & 14 & $0,77 \%$ \\
\hline Cristo Re & 1929 & 1316 & $68,22 \%$ & 1272 & 44 & $3,34 \%$ \\
\hline Policlinico Gemelli & 3697 & 3697 & $100,00 \%$ & 3323 & 374 & $10,12 \%$ \\
\hline San Filippo Neri & 951 & 933 & $98,11 \%$ & 820 & 113 & $12,11 \%$ \\
\hline Ospedale San Pietro FBF & 4545 & 3954 & $87,00 \%$ & 3954 & 604 & $15,28 \%$ \\
\hline Aurelia Hospital & 444 & 424 & $95,50 \%$ & 414 & 10 & $2,36 \%$ \\
\hline S Maria di Leuca & 94 & 85 & $90,43 \%$ & 85 & 0 & $0,00 \%$ \\
\hline O. S. Paolo & 427 & 427 & $100,00 \%$ & 425 & 2 & $0,47 \%$ \\
\hline P.O. Anzio Nettuno & 545 & 532 & $97,61 \%$ & 527 & 5 & $0,94 \%$ \\
\hline P.O. Albano Genzano & 850 & 809 & $95,18 \%$ & 809 & 0 & $0,00 \%$ \\
\hline P.O. Paolo Colombo & 530 & 516 & $97,36 \%$ & 512 & 4 & $0,78 \%$ \\
\hline P.O. Latina Nord & 1705 & 1911 & $112,08 \%$ & 1909 & 1 & $0,05 \%$ \\
\hline P.O. Latina Centro & 836 & 836 & $100,00 \%$ & 835 & 1 & $0,12 \%$ \\
\hline P.O. Latina Sud & 625 & 625 & $100,00 \%$ & 623 & 2 & $0,32 \%$ \\
\hline Città di Aprilia & 580 & 400 & $68,97 \%$ & 398 & 2 & $0,50 \%$ \\
\hline Belcolle Viterbo & 1234 & 1234 & $100,00 \%$ & 930 & 304 & $24,64 \%$ \\
\hline San Camillo de Lellis & 526 & 418 & $79,47 \%$ & 413 & 5 & $1,20 \%$ \\
\hline Fabrizio Spaziani FR & 1352 & 1352 & $100,00 \%$ & 1067 & 285 & $21,08 \%$ \\
\hline Santissimia Trinità FR & 910 & 491 & $53,96 \%$ & 486 & 5 & $1,02 \%$ \\
\hline Santa Scolastica & 695 & 703 & $101,15 \%$ & 569 & 134 & $19,06 \%$ \\
\hline Total & 44,805 & 41,510 & $92.65 \%$ & 39,217 & 2891 & $7.37 \%$ \\
\hline
\end{tabular}

First stage screening in the birth centers of the Lazio region in 2016

This result is close to estimates in the United States that range from 1 to 3 per 1000 newborns [1] and to that of other Italian studies [18, 20, 24, 25, 27]. A study on prevalence of prelingual deafness in Italy published in 2007 showed 40,887 cases of prelingual sensorineural hearing impairment $\geq 60 \mathrm{~dB}$, with a prevalence in the Italian population of 0.72 per 1000 inhabitants [29]. These results could therefore confirm the validity of the screening organizational model developed in the Lazio region.

A significant number of children with a clinical diagnosis of hearing impairment had unilateral hearing loss, a condition that is often underestimated and untreated, in 
Table 4 Third stage screening results

\begin{tabular}{|c|c|c|c|}
\hline & Policlinico Umberto I & Policlinico Gemelli & Bambino Gesù \\
\hline Included (RF) & $44(12)$ & $114(75)$ & 207 \\
\hline Tested (\%) & $42(95.4)$ & $48(42.1)$ & $207(100)$ \\
\hline Normal Hearing (\%) & $18(42.9)$ & $31(64.6)$ & $178(86)$ \\
\hline Hearing Loss (\%) [RF] & $24(57.1)[4]$ & $17(35.4)$ & $29(14)$ \\
\hline Unilateral (\%) & $13(54.2)$ & $9(52.9)$ & $6(20.7)$ \\
\hline Mild (\%) & $3(23.1)$ & $6(66.7)$ & $--(-)$ \\
\hline Moderate (\%) & $5(38.5)$ & $--(-)$ & $3(50)$ \\
\hline Severe (\%) & $2(15.4)$ & $1(11.1)$ & $2(30)$ \\
\hline Profound (\%) & $3(23.1)$ & $2(22.2)$ & $1(20)$ \\
\hline Bilateral (\%) & $11(45.8)$ & $8(47.1)$ & $23(79.3)$ \\
\hline Mild (\%) & $--(-)$ & $--(-)$ & $--(-)$ \\
\hline Moderate (\%) & $6(54.5)$ & $8(100)$ & $7(30.4)$ \\
\hline Severe (\%) & $3(27.3)$ & $--(-)$ & $4(17.4)$ \\
\hline Profound (\%) & $2(18.2)$ & $--(-)$ & $11(47.8)$ \\
\hline
\end{tabular}

Third stage screening performed in Level III centers of the Lazio region in 2016. RF: Risk Factors

part because of lack of awareness of possible consequences [30-33]. Usually, children with unilateral hearing loss enter a protocol of subsequent follow-up to monitor a possible evolution into bilateral forms. Also, screening may miss mild permanent hearing loss misdiagnosing it with a transitory conductive form. Due to the high percentage of unilateral hearing loss, it is therefore important to take this condition into account when evaluating and, especially, predisposing an intervention plan.

Our study highlighted several difficulties in the current procedures and methodologies of the UNHS program performed in the Lazio region that may also apply to other realities. One of the main issues is the incomplete data collection from Level II facilities due the absence of a functioning reporting network between these facilities and Level I and III structures, further worsened by the lack of coordination from central regional offices. Our analysis is based on data from about 35\% of Level II centers; this did not allow a consistent analysis of second stage screening with potential serious consequences not only on UNHS monitoring, but also on the effectiveness of the program with increased number of lost to follow-up (LFU) children and delayed diagnosis of hearing loss. Furthermore, the lack of data sharing from Level II facilities does not allow differentiating between well born children with a "refer" response at first stage and children with risk factors that are sent directly to second stage screening. Data from Level I facilities are transmitted and tracked by the monitoring office at the Lazio region allowing correct reporting of coverage. It would be auspicial to also extend such monitoring activity to Level II and Level III facilities, as already in place in some other Italian regions $[18,19]$.

There are some additional important data that are missing from this study. The first is the number of babies with risk factors. A study from Ghirri et al. [24] reported a prevalence of $6.1 \%$ in the Pisa hospital; Molini [19] reported a prevalence of $3.8 \%$ in Umbria. Data from the literature describe a prevalence between 3\% and 5\% of neonatal risk factors for hearing loss in the general population. In the Lazio region, the number of children with neonatal or maternal risk factors was not tracked at a central level, and therefore this data was not included in the present study. Secondarily, but not less important, age of patients included in third stage evaluation is unknown. Data for this stage were received directly from Level III facilities and were collected using different methodologies. Taken into account that all patients in Level III facilities followed the entire screening protocol, it could be assumed that diagnoses were performed within the first year of life. However, missing age data did not allow us to exactly evaluate the mean age of diagnosis. Moreover, no information about the beginning of audiological treatment was received.

Data about auditory neuropathy spectrum disorders (ANSD) were not available. In children with ANSD, the integrity of outer hair cells results in a "pass" response at TEOAE and therefore auditory dysfunction may remain undiagnosed at first stage evaluation [34-36]. To reduce the risk of undiagnosed ANSD, it is recommended to initiate auditory monitoring in babies with risk factors and instruct families of children who pass first stage to perform a further audiological evaluation if they notice abnormalities of auditory behavior in their children. Data from ANSD have not been collected in the present study; however, prevalence and natural history of ANSD is still largely unknown and possible revision of current screening protocols may be warranted as more information on these disorders become available [27]. 
LFU babies (newborns who fail the initial testing and are lost during follow-up) represent a common and alarming problem in UNHS [37-39]. In our study, data from Level III facilities showed an LFU rate $<5 \%$ for 2 centers, and a very high rate for the third center (Policlinico Gemelli). The data from the third center could be explained by regional or national mobility of these patients and may be biased by the unexpectedly very high number of babies with risk factors reported by that center. Instead, data about LFU patients between first and second and between second and third stages are not available. The collection of this data is necessary and important to monitor and actuate intervention strategies aimed to limit the number of LFU patients, such as targeted training to the personnel involved in screening procedures and appropriate education about UNHS and the risk factors of undiagnosed hearing impairment to pediatricians, neonatologists and gynecologists, and families. Better communication between centers and central regional offices is of utmost importance to limit LFU patients and increase effectiveness of UNHS.

Last, a noteworthy problem of UNHS that was encountered in our analysis is the heterogeneity between Level I centers in performing an A-TEOAE retest on refer children before addressing them to Level II centers. The utility of this retest has been demonstrated in several studies, allowing a drastic reduction of false positives and, therefore, of the workload for Level II and III facilities $[24,40]$. However, in the Lazio region not all facilities perform such retest; this should be corrected and could explain the high variability of refer patients between Level I centers that ranged between $0 \%$ of some birth centers to over $20 \%$ of others (see Table 3 ).

\section{Conclusions}

A correct and early diagnosis of hearing loss is mandatory to prevent its linguistic, developmental and educational consequences; the spread of UNHS programs is the optimal solution to reach this goal. The implementation of a UNHS program at a regional level requires consistent organizational efforts and is characterized by interconnected processes, activities and reporting. The analysis of 2016 UNHS in the Lazio region - although preliminary allowed identification of several strengths and weaknesses of the program. The strengths included a correct spread and monitoring of UNHS among Level I facilities, with an adequate coverage rate, and the proper execution of audiological monitoring and diagnosis among Level III facilities. Weakness, instead, mainly consisted in lack of an efficient and automated central process for collecting, monitoring and reporting of data and information. Such lack may affect the overall effectiveness of the screening program; in fact, although single participants involved in the UNHS program appeared to be fully responsible for their activity, the central coordination by the Lazio regional offices only included the first stage of screening and is currently not extended to Level II and III facilities. It would be auspicial to increase effectiveness of the screening program and to favor a constant bidirectional flow of data between centers, stages and central monitoring offices.

\section{Abbreviations \\ ABR: Auditory Brainstem Responses; ANSD: auditory neuropathy spectrum disorders; DPOAE: Distortion Product Otoacoustic Emissions; ELA: Levels of Assistance; JCIH: Joint Committee on Infant Hearing; LFU: lost to follow-up; NICU: neonatal intensive care units; TEOAE: Transient Evoked Otoacoustic Emissions; UNHS: Universal newborn hearing screening}

\section{Acknowledgements}

We thank the Lazio region for its contributions in funding this UNHS program. We thank the neonatology and audiology unit personnel of the Policlinico Umberto I, Policlinico Gemelli and Bambino Gesù Hospital for their collaboration in the realization of our UNHS program, and Dr. Francesca Cianfrone who provided data for the Level II center "San Camillo Hospital". We also wish to thank all the personnel involved in Level I and Level II auditory screening centers in the Lazio region.

Availability of data and materials

All data generated or analysed during this study are included in this published article and its supplementary information files.

\section{Authors' contributions}

Conceived and designed the experiments: MR, RT. Collected data: GC, SF, PM, AS. Analysed the data: SG, FR, GC. Wrote the paper: MR, AG. Provided critical review of the paper: $\mathrm{PP}, \mathrm{PO}$. All authors read and approved the final manuscript.

Ethics approval and consent to participate

Not applicable

\section{Consent for publication}

Not applicable

Competing interests

The authors declare that they have no competing interests.

\section{Publisher's Note}

Springer Nature remains neutral with regard to jurisdictional claims in published maps and institutional affiliations.

\section{Author details}

${ }^{1}$ Department of Sense Organs, Sapienza University of Rome, Rome, Italy. ${ }^{2}$ Department of Head and Neck Surgery, Institute of Otorhinolaryngology, Catholic University of Sacred Heart, Rome, Italy. ${ }^{3}$ Department of Surgery, Audiology and Otosurgery Unit, Bambino Gesù Pediatric Hospital, Rome, Italy. ${ }^{4}$ Department of Pediatrics, Division of Neonatology, Catholic University of Sacred Heart, Rome, Italy.

Received: 8 June 2018 Accepted: 6 August 2018

Published online: 24 August 2018

\section{References}

1. Vohr B. Overview: infants and children with hearing loss-part I. Ment Retard Dev Disabil Res Rev. 2003;9:62-4

2. Vohr B. Infants and children with hearing loss--part 2: overview. Ment Retard Dev Disabil Res Rev. 2003;9:218-9.

3. Berg AO, Allan JD, Frame PS, Homer CJ, Johnson MS, Klein JD, Lieu TA, Mulrow $C D$, Orleans $C T$, Peipert JF, et al. Newborn hearing screening: recommendations and rationale. Am J Nurs. 2002;102:83-9.

4. Davis A, Smith P, Ferguson M, Stephens D, Gianopoulos I. Acceptability, benefit and costs of early screening for hearing disability: a study of potential screening tests and models. Health Technol Assess. 2007;11:1-294. 
5. Linssen AM, Joore MA, Theunissen EJ, Anteunis $L$. The effects and costs of a hearing screening and rehabilitation program in residential care homes for the elderly in the Netherlands1. Am J Audiol. 2013;22:186-9.

6. Uus K, Bamford J, Taylor R. An analysis of the costs of implementing the National Newborn Hearing Screening Programme in England. J Med Screen. 2006;13:14-9.

7. Bubbico L, Bartolucci MA, Broglio D. Boner a: [societal cost of pre-lingual deafness]. Ann lg. 2007;19:143-52.

8. Sloot F, Hoeve HL, de Kroon ML, Goedegebure A, Carlton J, Griffiths HJ, Simonsz HJ, Group EUS. Inventory of current EU paediatric vision and hearing screening programmes. J Med Screen. 2015;22:55-64.

9. Mehl AL, Thomson V. The Colorado newborn hearing screening project, 1992-1999: on the threshold of effective population-based universal newborn hearing screening. Pediatrics. 2002;109:E7.

10. Wroblewska-Seniuk KE, Dabrowski P, Szyfter W, Mazela J. Universal newborn hearing screening: methods and results, obstacles, and benefits. Pediatr Res. 2017;81:415-22.

11. Force USPST. Universal screening for hearing loss in newborns: US preventive services task force recommendation statement. Pediatrics. 2008; 122:143-8.

12. Downs MP, Yoshinaga-Itano C. The efficacy of early identification and intervention for children with hearing impairment. Pediatr Clin N Am. 1999; 46:79-87.

13. Caluraud S, Marcolla-Bouchetemble A, de Barros A, Moreau-Lenoir F, de Sevin E, Rerolle S, Charriere E, Lecler-Scarcella V, Billet F, Obstoy MF, et al. Newborn hearing screening: analysis and outcomes after 100,000 births in upper-Normandy French region. Int J Pediatr Otorhinolaryngol. 2015;79: 829-33.

14. American Academy of Pediatrics JColH. Year 2007 position statement: principles and guidelines for early hearing detection and intervention programs. Pediatrics. 2007;120:898-921.

15. Joint Committee on Infant $\mathrm{H}$, American Academy of A, American Academy of $P$, American Speech-Language-Hearing A, Directors of S, Hearing Programs in State H, Welfare A. Year 2000 position statement: principles and guidelines for early hearing detection and intervention programs. Joint Committee on Infant Hearing, American Academy of Audiology, American Academy of Pediatrics, American Speech-Language-Hearing Association, and Directors of Speech and Hearing Programs in State Health and Welfare Agencies. Pediatrics. 2000;106:798-817.

16. Patel H, Feldman M. Universal newborn hearing screening. Paediatr Child Health. 2011;16:301-10

17. Orzan E, Ruta F, Bolzonello P, Marchi R, Ceschin F, Ciciriello E. Childhood hearing surveillance activity in Italy: preliminary recommendations. Acta Otorhinolaryngol Ital. 2016;36:15-20.

18. Calevo MG, Mezzano P, Zullino E, Padovani P, Scopesi F, Serra G, Stern G. Neonatal hearing screening model: an Italian regional experience. J Matern Fetal Neonatal Med. 2007;20:441-8.

19. Molini E, Calzolaro L, Lapenna R, Ricci G. Universal newborn hearing screening in Umbria region, Italy. Int J Pediatr Otorhinolaryngol. 2016; 82:92-7.

20. Berrettini S, Ghirri P, Lazzerini F, Lenzi G, Forli F. Newborn hearing screening protocol in tuscany region. Ital J Pediatr. 2017;43:82.

21. Marciano E, Laria C, Malesci R, ladicicco P, Landolfi E, Niri C, Papa C, Franze A, Auletta G. Newborn hearing screening in the Campania region (Italy): early language and perceptual outcomes of infants with permanent hearing loss. Acta Otorhinolaryngol Ital. 2013;33:414-7.

22. Martines F, Porrello M, Ferrara M, Martines M, Martines E. Newborn hearing screening project using transient evoked otoacoustic emissions: western Sicily experience. Int J Pediatr Otorhinolaryngol. 2007;71:107-12.

23. Ciorba A, Hatzopoulos S, Busi M, Guerrini P, Petruccelli J, Martini A. The universal newborn hearing screening program at the University Hospital of Ferrara: focus on costs and software solutions. Int J Pediatr Otorhinolaryngol. 2008;72:807-16.

24. Ghirri P, Liumbruno A, Lunardi S, Forli F, Boldrini A, Baggiani A, Berrettini S. Universal neonatal audiological screening: experience of the University Hospital of Pisa. Ital J Pediatr. 2011:37:16.

25. Magnani C, Bacchi G, Borghini AM, Delmonte D, Fava G, Occasio AM, Sarti A, Vincenti V. Universal newborn hearing screening: the experience of the University Hospital of Parma. Acta Biomed. 2015;86:273-7.
26. Pastorino G, Sergi P, Mastrangelo M, Ravazzani P, Tognola G, Parazzini M, Mosca F, Pugni L, Grandori F. The Milan project: a newborn hearing screening programme. Acta Paediatr. 2005;94:458-63.

27. De Capua B, Costantini D, Martufi C, Latini G, Gentile M, De Felice C. Universal neonatal hearing screening: the Siena (Italy) experience on 19,700 newborns. Early Hum Dev. 2007;83:601-6.

28. Bubbico L, Tognola G, Grandori F. Evolution of Italian universal newborn hearing screening programs. Ann Ig. 2017;29:116-22.

29. Bubbico L, Rosano A, Spagnolo A. Prevalence of prelingual deafness in Italy. Acta Otorhinolaryngol Ital. 2007;27:17-21.

30. Tharpe AM. Unilateral and mild bilateral hearing loss in children: past and current perspectives. Trends Amplif. 2008;12:7-15.

31. Propst EJ, Greinwald JH, Schmithorst V. Neuroanatomic differences in children with unilateral sensorineural hearing loss detected using functional magnetic resonance imaging. Arch Otolaryngol Head Neck Surg. 2010;136:22-6

32. Polonenko MJ, Papsin BC, Gordon KA. Delayed access to bilateral input alters cortical organization in children with asymmetric hearing. Neuroimage Clin. 2018;17:415-25.

33. Grandpierre V, Fitzpatrick EM, Na E, Mendonca O. School-aged children with mild bilateral and unilateral hearing loss: Parents' reflections on services, experiences, and outcomes. J Deaf Stud Deaf Educ. 2017:1-8.

34. Pham NS. The management of pediatric hearing loss caused by auditory neuropathy spectrum disorder. Curr Opin Otolaryngol Head Neck Surg. 2017;25:396-9

35. Boudewyns A, Declau F, van den Ende J, Hofkens A, Dirckx S, Van de Heyning P. Auditory neuropathy spectrum disorder (ANSD) in referrals from neonatal hearing screening at a well-baby clinic. Eur J Pediatr. 2016;175:993-1000.

36. Uus K, Young A, Day M. Parents' perspectives on the dilemmas with intervention for infants with auditory neuropathy spectrum disorder: a qualitative study. Int J Audiol. 2015;54:552-8.

37. Nikolopoulos TP. Neonatal hearing screening: what we have achieved and what needs to be improved. Int J Pediatr Otorhinolaryngol. 2015;79:635-7.

38. Ricalde RR, Chiong CM, Labra PJP. Current assessment of newborn hearing screening protocols. Curr Opin Otolaryngol Head Neck Surg. 2017;25:370-7.

39. Cunningham $M$, Thomson V, McKiever E, Dickinson LM, Furniss A, Allison MA. Infant, Maternal, and Hospital Factors' Role in Loss to Follow-up After Failed Newborn Hearing Screening. Acad Pediatr. 2017;

40. Langagne $T$, Schmidt $P$, Leveque $M$, Chays $A$. Universal hearing screening in the Champagne-Ardenne regions: results and consideration after 55000 births from January 2004 to June 2007. Rev Laryngol Otol Rhinol (Bord). 2008;129:153-8
Ready to submit your research? Choose BMC and benefit from:

- fast, convenient online submission

- thorough peer review by experienced researchers in your field

- rapid publication on acceptance

- support for research data, including large and complex data types

- gold Open Access which fosters wider collaboration and increased citations

- maximum visibility for your research: over $100 \mathrm{M}$ website views per year

At $\mathrm{BMC}$, research is always in progress.

Learn more biomedcentral.com/submissions 